\title{
As expectativas dos alunos e os objetivos de um curso de língua inglesa: influências sobre a aprendizagem
}

\author{
Anselmo Pereira de Lima (LIMA, Anselmo P. de) \\ Professor Doutor da Universidade Tecnológica Federal do Paraná - UTFPR \\ selmolima@hotmail.com
}

\begin{abstract}
Resumo
O objetivo deste trabalho foi investigar de que forma as expectativas dos alunos e os objetivos de um curso de Língua Inglesa oferecido em uma empresa ferroviária concorrem para influenciar a aprendizagem. Como fundamentação teórica, foi empregada a hipótese do filtro afetivo de Krashen, à luz da qual foram analisadas uma aula do curso e uma entrevista que reuniu e envolveu todos os alunos. Os dados apontaram para certa correspondência entre as expectativas dos alunos e os objetivos do curso, o que parece gerar um baixo filtro afetivo e, assim, propiciar a aprendizagem.
\end{abstract}

Palavras-chave: filtro afetivo, expectativas dos alunos, objetivos do curso, aprendizagem de uma segunda língua.

\begin{abstract}
The aim of this study was to investigate how the interaction between students' expectations and the objectives of an English Language course offered in a railroad company influences the learning process. The research was based on Krashen's Affective Filter Hypothesis, in light of which one class of the course and one interview involving all the students were analyzed. The data indicated there was a correspondence between students' expectations and course objectives, which appears to generate a low affective filter and, thus, promote learning.
\end{abstract}

Keywords: affective filter, student expectations, course objectives, second language learning. 
Como se sabe, a separação entre a parte intelectual da nossa consciência e sua parte afetiva e volitiva é um dos defeitos radicais de toda a psicologia tradicional. (L. S. VIGOTSKI, 2001, p. 16)

\section{Introdução}

Este trabalho teve por objetivo investigar de que forma as expectativas dos alunos e os objetivos de um curso de Língua Inglesa concorrem para influenciar a aprendizagem. A ideia de realizar essa investigação surgiu a partir de uma intuição, a qual me dizia que, de um lado, os alunos de língua estrangeira vêm para a aula trazendo suas expectativas e que, de outro, a aula em si tem seus objetivos, os quais - em conjunto com as expectativas dos alunos - podem influenciar de alguma forma a aprendizagem. Posteriormente, as seguintes afirmações de dois de meus alunos me fizeram refletir um pouco mais sobre essa intuição e levá-la a sério:

"Eu acho que isso é que mata numa escola. Passou. Virar a folha, entendeu? Virou a folha e acabou. Não quer saber o grupo como está" (Júlia).

"O nosso curso, o nosso professor, ele tem essa sensibilidade. Ele deixa voltar. A ordem normal é essa aqui, mas repete de novo 'olha, é assim, capítulo tal, livro tal'” (Ricardo).

"E ainda fala isso sem dar bronca” (Júlia).

A fala de Júlia, como é possível perceber, aponta para certo curso de língua estrangeira em escolas cujas aulas têm objetivos específicos que são buscados independentemente das expectativas e necessidades dos alunos. A fala de Ricardo, ao contrário, parece revelar um curso de língua estrangeira cujas aulas têm objetivos que levam em conta aquilo que os alunos esperam e precisam, ou seja, suas expectativas e necessidades. Essa fala, como se pode ver, é corroborada pela fala seguinte de Júlia: " $E$ ainda fala isso sem dar bronca". Com base nessa intuição e nas afirmações de meus alunos, lancei a seguinte questão de pesquisa:

De que forma a expectativa dos alunos e os objetivos de um curso de Língua Inglesa oferecido em uma empresa ferroviária concorrem para influenciar a aprendizagem?

A seguir, o leitor encontrará o relato de um estudo realizado para que se pudesse responder a essa questão. Antes da apresentação desse relato, é importante apenas ressaltar os seguintes pontos:

1) a fundamentação teórica apresentada e empregada a seguir consiste na polêmica e já bastante conhecida e discutida hipótese do filtro afetivo de Krashen;

2) não é a proposta deste texto apresentar um estudo ou argumentos que venham a confirmar ou infirmar a referida hipótese: sendo ela aqui apresentada e empregada, sua validade é obviamente pressuposta;

3) a contribuição deste trabalho para a área de Linguística Aplicada, não sendo a confirmação ou infirmação dessa hipótese, consiste: a) na apresentação e discussão de uma situação singular de ensino-aprendizagem de Língua Inglesa envolvendo um professor-pesquisador e um grupo de 5 alunos no interior de uma empresa ferroviária; 
b) na apresentação, análise e discussão de dados e detalhes relativos a essa situação singular de ensino-aprendizagem, os quais poderão ser de utilidade para profissionais que atuam na promoção de cursos de línguas em situações semelhantes, especialmente por se tratar do resultado da inevitável interação das expectativas dos alunos com os objetivos de um curso de língua estrangeira.

4) o objetivo deste artigo é investigar de que forma os já referidos objetivos e expectativas concorrem para influenciar a aprendizagem.

\section{Fundamentação teórica}

Este trabalho se apoia, principalmente, na hipótese do filtro afetivo de Krashen (1982; 1985). Variáveis afetivas estão relacionadas com a aprendizagem de uma segunda língua (ALMEIDA FILHO, 2007, p. 17; RUBIN; THOMPSON, 1994, p. 10) e as melhores situações para que essa aprendizagem ocorra são aquelas que promovem baixos níveis de ansiedade, os quais podem ser traduzidos e compreendidos como um baixo filtro afetivo (KRASHEN; TERREL, 1983, p. 38).

Krashen e Terrel (1983, p. 38-39) dizem que o filtro afetivo, quando alto, age para impedir que o input seja usado para a aprendizagem de uma língua e que as salas de aula que promovem um baixo filtro afetivo são aquelas que geram pouca ansiedade entre os alunos, mantendo-os abertos para receber o input e, consequentemente, proporcionando a aprendizagem. A ideia de que quanto mais baixo o nível de ansiedade dos alunos maior é o grau de aprendizagem da língua estrangeira está presente também em Khuwaileh, que, entretanto, sem contradizer essa perspectiva, considera que certa dose de ansiedade pode ser produtiva no processo de aprendizagem:

Embora a ansiedade possa até certo ponto ser positiva por equivaler, às vezes, a um estado de alerta e prontidão, ela pode dificultar a aprendizagem se os alunos estiverem ansiosos em grande medida. Isso quer dizer que uma quantidade razoável de ansiedade é útil para os alunos porque eles passam a agir com seriedade, mas uma quantidade excessiva de ansiedade dificulta a aprendizagem porque eles não conseguem relaxar. Do ponto de vista psicológico, um aluno relaxado e confiante aprende melhor do que um aluno ansioso e inseguro. (KHUWAILEH, 1995, p. 62) ${ }^{1}$

Assim, verifica-se em Khuwaileh que não se trata de eliminar a ansiedade do processo de aprendizagem, mas de produzi-la na medida certa, de modo que não se percam alguns dos benefícios que dela podem advir, tais como um estado de alerta e prontidão e uma postura mais séria da parte dos alunos. Mas ansiedade em quantidade excessiva gera um alto filtro afetivo e, de acordo com Krashen (1985, p. 3), quando o filtro afetivo está alto, o aluno pode até entender o que ouve ou lê, porém esse input não chegará até o LAD (language acquisition device ${ }^{2}$ ) e, nessas condições, não ocorrerá a

\footnotetext{
${ }^{1}$ Texto original: Although anxiety, to a certain extent, could be positive as it is sometimes synonymous with alertness and readiness, it makes learning difficult if students feel anxious to a great extent. That is to say, a reasonable amount of anxiety is helpful to students because they become serious, but an extreme amount of it makes their learning difficult because they feel not relaxed. Psychologically, a relaxed and confident student learns better than an anxious and unstable one.

${ }^{2}$ Literalmente, “dispositivo de aquisição da linguagem”. Krashen adota em sua teoria o conceito de LAD desenvolvido por Chomsky, para quem a capacidade que tem o ser humano de falar e compreender uma ou mais línguas deve-se à existência de um dispositivo inato, interno ao organismo humano e não
} 
aprendizagem. Segundo o autor, isso ocorre quando o aluno está sem motivação, sem auto-confiança ou ansioso; quando o aluno está na defensiva e vê a sala de aula como um local onde seus pontos fracos serão revelados (cf. também RODRIGUES; CUNHA, 1984, p. 1-8; ROGERS, 1969, p. 157-163). Ainda conforme Krashen (1985, p. 3), quando o filtro afetivo está baixo, o aluno não está preocupado com a possibilidade de ser mal sucedido na aprendizagem da língua e vê a si mesmo como um membro potencial do grupo de falantes da língua estrangeira. O autor (1985, p. 3) sugere, ainda, que o filtro está o mais baixo possível quando o aluno está tão envolvido com a mensagem que, temporariamente, se esquece de que está ouvindo ou lendo em outra língua.

O conceito de filtro afetivo proposto por Krashen (1985, p. 1) corresponde a uma de suas cinco hipóteses de aprendizagem de uma língua estrangeira, as quais constituem, de acordo com o autor, uma teoria. ${ }^{3}$ Essa teoria tem sido muito criticada e questionada, porém há alguns críticos que, além de criticar e questionar, também destacam pontos da teoria que dizem ser verdadeiros e com os quais concordam. É o caso de Marton, que ressalta em sua crítica a Krashen sua concordância com o fato de que:

se o professor deixar de criar uma atmosfera amistosa na sala de aula, assim forçando os alunos a recorrer àquilo que os psicólogos humanistas chamam de "aprendizagem defensiva", é claro que isso será uma falha de natureza educacional, já que a psicologia da educação nos diz que o afetivo dos alunos é tão importante em qualquer tipo de trabalho de ensino-aprendizagem quanto o cognitivo.

(MARTON, 1994, p. 61-62)

O autor conclui, com isso, que a noção do filtro afetivo, tão importante à teoria de Krashen, pode ser aplicada a qualquer processo de aprendizagem e não somente à aprendizagem de uma segunda língua (cf. MARTON, 1994, p. 62). A conclusão desse autor é corroborada por Cazden (2001, p. 77), para quem tanto os aspectos afetivos quanto os aspectos cognitivos estão ligados à aprendizagem em geral.

\section{Metodologia}

A seguir, apresento de modo detalhado e objetivo informações indispensáveis para a compreensão do estudo realizado: sobre o contexto da pesquisa, sobre os participantes e sobre o processo de coleta e análise de dados. Penso que a forma com que apresento essas informações facilita a compreensão do leitor, tornando o texto diretamente acessível também para não-especialistas. Pode, entretanto, causar em alguns leitores mais especializados a impressão de que se trata de uma "metodologia

determinado inteiramente pelo mundo exterior, cuja finalidade é permitir que se constitua a competência linguística do falante (KENEDY, 2008, p. 129).

\footnotetext{
${ }^{3}$ Para uma síntese dessa teoria, vide Richards e Rodgers (1986/2008, p. 178-191).

${ }^{4}$ Texto original: If the teacher fails to create a warm and friendly atmosphere in the classroom and thus makes the learner resort to what humanistic psychologists call "defensive learning," it is clear that this is a fault of a general educational nature, since the psychology of learning tells us that the learner's affective domain is as important in any kind of learning as the cognitive one.
} 
simplista”. Talvez o seja, de fato. Entretanto, se por um lado alguns podem considerá-la assim, por outro, não podem negar que ela seja adequada à proposta do trabalho.

Além disso, o mais importante em Ciências Humanas, como o diz Bakhtin (1979/2003, p. 307-335) e - em sua esteira - Amorim (2001, p. 80-91), é que, do ponto de vista metodológico, o texto nunca seja perdido de vista. E justamente ele, o texto, sem o qual não poderia haver pesquisa em Linguística Aplicada, é o foco privilegiado dessa metodologia, como se verificará adiante.

\section{Contexto de pesquisa}

A pesquisa foi realizada com um grupo de cinco alunos que faziam o curso de Inglês com um professor particular contratado pelo próprio grupo. Esse professor foi o próprio pesquisador, o que - nesse caso - confere a este trabalho certo caráter de pesquisa-ação (THIOLLENT, 2004) ou de reflexão sobre a ação (cf. ALARCÃO, 2005). As aulas ocorriam duas vezes por semana, após o expediente, na empresa ferroviária onde os alunos trabalhavam. Cada aula tinha duração mínima de sessenta e máxima de noventa minutos. Os alunos encerravam seu dia de trabalho às $17 \mathrm{~h} 20 \mathrm{~min}$ e iniciavam o curso às $17 \mathrm{~h} 30 \mathrm{~min}$. Tinham, portanto, dez minutos para deixar o trabalho e se deslocar até a sala onde ocorriam as aulas.

\section{Participantes}

Os participantes tinham média de idade de 45 anos. Eram dois engenheiros (Rodrigo e Paulo), dois técnicos (Pedro e Ricardo) e uma psicóloga (Júlia). Quando iniciaram o curso de Língua Inglesa no primeiro semestre de 2002, diziam que queriam aprender a falar a língua e também escrever, ler e entender o que ouviam. Em suas palavras, solicitaram um curso que tivesse início "partindo do zero". Os alunos vinham estudando juntos há aproximadamente um ano e meio e, ao longo desse tempo, davam evidências de aprendizagem.

Trata-se, como apresentado no item "Contexto de pesquisa”, de alunos que estudam inglês não em uma escola de idiomas, mas no interior da própria empresa em que trabalham. Com base em Ellis e Johnson (1994/1996, p. 15-19), esse tipo de aluno pode ser classificado em três categorias: 1) aprendizes sem experiência profissional; 2) aprendizes com pouca experiência profissional; e 3) aprendizes com experiência profissional. Os participantes podem ser classificados nesta última categoria. Segundo Ellis e Johnson (1994/1996, p. 18), esse tipo de aluno pode ter atitudes ou estilos que podem funcionar como obstáculos à aprendizagem, tornando-se importante que o professor seja flexível com relação aos objetivos a serem alcançados de modo individual e coletivo.

\section{Coleta de dados}

Para que a pesquisa se realizasse, gravei em áudio uma aula com duração de setenta minutos, seguida de entrevista aberta com o grupo de alunos. A fim de identificar e explicitar os objetivos da aula, utilizei também o plano dessa aula, o qual - 
no quadro deste trabalho - entra como um dado suplementar, o que - como se verá adiante - permite uma determinada triangulação na análise dos dados.

\title{
O plano de aula: sequência de atividades
}

Meu objetivo não é aqui cotejar o plano de aula com aquilo que nela efetivamente ocorre. Isso seria assunto para outro trabalho, que poderia ser realizado, por exemplo, do ponto de vista da distância sempre existente entre trabalho docente prescrito e trabalho docente realizado (cf. MACHADO, 2004). Portanto, por julgar que isso será útil no momento das análises, limito-me aqui a apresentar, com base nesse plano de aula, a sequência das atividades [a serem] desenvolvidas pelo professor com os alunos: 1) os alunos falam um pouco a respeito de como foi seu dia; 2) os alunos supõem que não tiveram um bom dia de trabalho porque tiveram alguns problemas de saúde; 3) o professor ajuda os alunos a relembrar como se dizem alguns problemas de saúde em inglês; 4) o professor diz aos alunos que sempre que temos algum problema de saúde, sempre há alguém para dar uma "receita" do que se deve fazer para melhorar; 5) os alunos, utilizando seus livros, associam problemas de saúde a possíveis "receitas"; 6) os alunos fazem conversações em pares, simulando situações em que, no trabalho, um tem um problema de saúde e o outro dá "receitas"; 7) os alunos ouvem uma conversação semelhante àquela que fizeram (ver item 6) e tentam identificar o problema de saúde que uma pessoa tem e a receita que a outra dá.

\section{A aula: os objetivos}

A partir da sequência das atividades explicitadas no item "O plano de aula: sequência de atividades”, pode-se dizer que os objetivos da aula foram: revisar alguns problemas de saúde já estudados em aulas anteriores e apresentar alguns novos; apresentar possíveis "receitas" para os problemas de saúde estudados; promover conversações em que os alunos, em pares, pudessem praticar diálogos nos quais um tem um problema de saúde e o outro dá "receitas" utilizando o verbo modal "should" (apresentado pela primeira vez no curso); e proporcionar a oportunidade de os alunos ouvirem e compreenderem um diálogo parecido com aquele que praticaram.

Segue a estrutura básica estudada e praticada em aula:

\author{
A: Hi, Peter. How are you? \\ $B$ : Not so good. I have a cold. \\ A: Really? That's too bad. I think you should take some vitamin C.
}

Além dos objetivos da aula expostos anteriormente, é necessário ressaltar que havia um objetivo maior subjacente a todas as aulas: que o curso caminhasse de acordo com o desenvolvimento ou ritmo dos alunos. Acredito ser esse o objetivo mais relevante para este estudo. Esse aspecto será melhor explorado adiante, no item "Identificação dos objetivos do curso na entrevista”.

\section{A entrevista}

A entrevista foi aberta e realizada com todos os alunos ao mesmo tempo, os quais se alternaram para dar suas respostas. As perguntas feitas aos alunos foram as seguintes: 
1) Com que objetivos [expectativas] você vem para cá estudar inglês?

2) Os objetivos [expectativas] que vocês têm interferem na aula? Eles vêm à tona na sua mente e influenciam seu andamento na aula?

3)De que forma o dia de trabalho de vocês influencia a aula?

Na ocasião em que este trabalho estava em desenvolvimento, a palavra “expectativas” ainda não estava sendo empregada. Inicialmente, foi utilizada a palavra “objetivos”. É por essa razão que, nas perguntas da entrevista, aparece esta última. Acredito que a posterior substituição da palavra “objetivos" por "expectativas” tenha proporcionado um avanço no que se refere à terminologia empregada e à maneira de se conceberem os elementos a que os termos se referem. Além disso, o fato de a palavra "objetivos" ter sido utilizada na entrevista parece não ter influenciado significativamente os dados gerados e as conclusões a que cheguei, como se perceberá a seguir.

\section{Análise dos dados}

Para a análise dos dados, ouvi a gravação cuidadosamente, buscando identificar os momentos em que as expectativas dos alunos e os objetivos do curso emergiam na aula e na entrevista para transcrevê-los Em seguida, realizei a análise à luz da hipótese do filtro afetivo de Krashen.

\section{Análise e resultados}

\section{Identificação dos objetivos do curso na entrevista}

Minha fala como professor em entrevista com os alunos revela, de modo geral, os objetivos do curso de língua inglesa que eu estava oferecendo:

"É o que eu falei para vocês. O curso vai caminhar conforme o desenvolvimento do grupo, no ritmo do grupo" (Anselmo).

A reação dos alunos à minha fala fica muito bem representada na afirmação de um dos alunos, o qual se pronuncia em nome do grupo e tem sua colocação corroborada pelos colegas:

"E é assim que tem sido. No ritmo do grupo" (Júlia).

Acredito ser esse o objetivo do curso que mais interagia com as expectativas dos alunos, assim influenciando a aprendizagem. Os objetivos da aula expostos anteriormente no item "A aula: os objetivos" também tinham sua parcela de contribuição, porém, de acordo com minha percepção, tinham menor relevância.

\section{Identificação das expectativas dos alunos na entrevista}

Há evidências de que as expectativas dos alunos com relação ao curso de língua inglesa ficam bem representadas, de modo geral, pela seguinte fala de um dos participantes: 
"Já tentei fazer em escolas, mas eu acho que a pressão foi demais para mim e, devido ao tipo de vida que eu levo, não deu certo” (Júlia).

Essa fala aponta para um aluno que tem a expectativa de que seu curso seja "sem pressão" e que, ao mesmo tempo, possibilite conciliar "o tipo de vida" que leva com seus estudos. Segue outra colocação de um aluno, que parece ter a mesma expectativa:

"A Júlia já tinha mencionado antes que você fazer em uma escola é diferente. Realmente é diferente. Por que é diferente? Você tem a obrigação de fazer aquilo. Muito embora não seja uma coisa que você está fazendo obrigado, você está fazendo porque quer. Na escola você é cobrado, você tem a obrigação de mostrar que aprendeu alguma coisa” (Rodrigo).

A “pressão” mencionada por Júlia se traduz na fala de Rodrigo em "obrigação de fazer", de "mostrar que aprendeu alguma coisa" e na cobrança excessiva de que o aluno é, talvez, vítima. A fala desses dois alunos parece denunciar cursos de língua inglesa, em escolas, nos quais (também de acordo com minha experiência profissional) o curso tem andamento próprio e, muitas vezes, avança visando a cumprir o programa, frequentemente deixando alguns dos alunos para trás. Tal situação aponta para a geração de um alto filtro afetivo que contribui para impedir que a aprendizagem ocorra, frustrando o aluno e deixando-o ansioso. O resultado é que esses alunos, muitas vezes, acabam desistindo de levar o curso adiante.

\section{Correspondência entre os objetivos do curso e as expectativas dos alunos}

Os dados mencionados nos itens "Identificação dos objetivos do curso na entrevista" e "Identificação das Expectativas dos alunos na entrevista" apontam para a correspondência entre os objetivos do curso de língua inglesa que estava sendo oferecido e as expectativas dos alunos com relação ao curso, o que parece gerar um baixo filtro afetivo e, assim, contribuir para que ocorra a aprendizagem. Isso fica ainda melhor evidenciado a partir das seguintes impressões de cada um dos alunos do grupo:

"E, não sei, aqui eu estou me soltando mais, eu estou vendo que eu estou aprendendo. Pouco que seja, porque eu não estou me esforçando como deveria, mas eu estou aprendendo um pouco" (Pedro).

"E além de tudo isso, aqui é muito relaxante para mim. Muito bom... fazer aula aqui. Eu acho que é sem pressão aqui. A sua aula pega no que a gente precisa, só que a gente precisa aproveitar melhor isso. É uma aula muito boa. A gente não fica desesperado pensando que tem que passar aqui, amanhã tem que vir. Não” (Júlia).

"A aula passa a ser motivante pela aula e a gente acaba esquecendo os objetivos [expectativas] e a aula acaba sendo fluida” (Ricardo).

"Aqui você aprende sem precisar demonstrar, você não tem a obrigação de demonstrar... Você aprende sem perceber! Eu acho que essa é a verdade. É, eu acho que é a verdade. Você praticando é que você aprende. Você aprende sem perceber!" (Rodrigo). 
"E como todos já falaram, a gente vem e aqui a gente relaxa, então, dá uma relaxada na mente. Sai do dia-a-dia e entra numa parte mais gostosa, que é o que nós queremos. A gente está querendo aprender. É uma vontade nossa" (Paulo).

Como se pode perceber, um dos fatores de geração de um baixo filtro afetivo durante as aulas, indispensável para que ocorra a aprendizagem (KRASHEN, 1983, p. 4), parece ser a correspondência entre os objetivos do curso de língua e as expectativas dos alunos. Isso, utilizando-se das palavras dos alunos, propiciará uma aula mais motivante, relaxante, fluida, sem pressão, na qual o aluno "se solta" e, em alguns momentos, "vê que está aprendendo” e, em outros, “aprende sem perceber”.

\section{A aula, os alunos e o professor}

A aula tinha seu início às $17 \mathrm{~h} 30 \mathrm{~min}$, dez minutos depois de os alunos terem deixado seus postos de trabalho na empresa. Pode-se dizer que ela possuía três momentos que chamam a atenção: 1) os cinco ou dez primeiros minutos; 2) o decorrer da aula; e 3) os cinco ou dez minutos finais. A seguir, tendo em vista que "só a análise dos processos que caracterizam a relação interacional entre o aluno e o professor na sala de aula pode apontar direções para a compreensão destes processos” (MOITA LOPES, 1996, p. 95), explorarei um pouco cada um desses momentos da aula, sempre tendo em vista e levando em conta os objetivos do curso, as expectativas dos alunos e a hipótese do filtro afetivo de Krashen.

\section{Primeiro momento: os cinco ou dez primeiros minutos da aula}

Quando os alunos chegavam para a aula, eu percebia que eles estavam cansados, sendo possível notar isso em seus semblantes. Era o fim de um dia de trabalho e eu observava que eles entravam em sala de aula e continuavam com seus pensamentos e preocupações voltados para suas atividades na empresa. Tipicamente, conversavam entre si sobre seus problemas e dificuldades que tinham enfrentado ou que vinham enfrentando. Muitas vezes, quando um aluno chegava um pouco atrasado para a aula, levava alguns minutos para se integrar ao grupo. Tentando falar sobre seu trabalho, chegava, finalmente, a interromper a aula que já se havia iniciado. É o que se pode ver a seguir:

$\begin{array}{ll}\text { Professor: } & \text { "Ok, everybody, I think we can start. All right? Ok. So } \\ & \text { let’s see. Everybody, how was your day at work } \\ & \text { today? How was your day today at work, Pedro?” } \\ \text { Pedro: } & \text { "Fine”. (com voz e entonação de cansaço, } \\ & \text { respondendo sem querer responder) } \\ \text { Professor: } & \text { "Fine? What did you do? What did you do today } \\ & \text { at work?” (nesse momento o diálogo é interrompido e } \\ & \text { há movimentação na sala de aula: é a chegada de um } \\ & \text { aluno atrasado) } \\ \text { Professor: } & \text { (dirigindo-se ao aluno atrasado) "Hello, Rodrigo. } \\ & \text { How are you? Are you ok?” (o aluno não responde e } \\ & \text { começa a conversar com seus colegas, em português, } \\ & \text { sobre certo problema com uma máquina da empresa) }\end{array}$




$\begin{array}{ll}\text { Professor: } & \text { "Are you ok, Rodrigo? Just a minute, Pedro. Are you } \\ & \text { ok, Rodrigo?" } \\ \text { Rodrigo: } & \text { "Yes". } \\ \text { Professor: } & \text { "Really? Did you have a nice day at work?” } \\ \text { Rodrigo: } & \text { "Oh, yes [...]” } \\ \text { Professor: } & \text { "Are you [...] Did you see the machine?" } \\ \text { Rodrigo: } & \text { "No". } \\ \text { Professor: } & \text { "The machine crashed, right?” } \\ \text { Todos os alunos: } & \text { "Yes". }\end{array}$

\section{Segundo momento: o decorrer da aula}

A essa altura, os alunos superavam os primeiros cinco ou dez minutos de início da aula, seus semblantes aparentavam menos cansaço e eles já conseguiam rir e até mesmo fazer brincadeiras com seus problemas e situações de trabalho. Coloco a seguir um diálogo para ilustrar esse aspecto:

$\begin{array}{ll}\text { Júlia: } & \text { "I'm not feeling very well”. } \\ \text { Ricardo: } & \text { "Really? What's the matter?” } \\ \text { Júlia: } & \text { "I have a cough”. } \\ \text { Ricardo: } & \text { "Oh, really? That’s too bad. I think you should is [...] } \\ \text { take } & \text { a drop [...] take a cough drops [...]” } \\ \text { Júlia: } & \text { "Cough drops?” } \\ \text { Ricardo: } & \text { "Yes! Or [...] é [...] see a doctor”. } \\ \text { Júlia: } & \text { "Uhn! my home?” } \\ \text { Ricardo: } & \text { (ri alto e olha para o professor) quer ir pra casa de } \\ & \text { qualquer jeito! } \\ \text { Júlia: } & \text { "No! My boss is Roberta. Isso não é possível”. } \\ \text { Ricardo: } & \text { (ri alto) } \\ \text { Júlia: } & \text { "My boss is ba.:.:... very bad”. (alongando o "a” de } \\ & \text { "bad" para ser dramática) }\end{array}$

\section{Terceiro momento: os cinco ou dez minutos finais da aula}

Nesses momentos, os alunos pareciam estar mais despreocupados, mais desligados de suas atividades de trabalho e mais ligados na aula. Apresentavam, também, semblantes menos tensos. Selecionei o seguinte trecho para tentar mostrar esses aspectos:
Professor:
“Ok?” (silêncio) "Ok? How do you say "descansar bastante" in the text?"
Júlia:
"A lot of rest?"
Professor:
"To get a lot of rest".
Todos os alunos:
(repetindo baixinho e anotando) "To get a lot of rest".
Professor:
"How do you say 'é útil, ajuda'?"
Júlia:
"It's really important?"
Pedro:
"It's helpful?"
Professor:
"It’s helpful... it’s helpful... É útil, ajuda”.

\section{A influência do trabalho dos alunos na aula}


Os dados obtidos na entrevista dão fortes evidências de que as impressões de aula descritas nos itens "Primeiro momento: os cinco ou dez primeiros minutos de aula", "Segundo momento: o decorrer da aula" e "Terceiro momento: os cinco ou dez minutos finais da aula" têm fundamento. Os alunos chegam "cansados" e "estressados" para o início da aula. Esse cansaço e estresse persistem ao longo dos primeiros cinco ou dez minutos de aula, são amenizados no decorrer do trabalho e parecem desaparecer próximo de seu término. Como dizem os alunos:

"Às vezes, conforme o ritmo de trabalho lá, eu chego... 5:20 eu digo 'eu não vou hoje, não tem condições, eu estou cansada, não vou'. Mas aí eu paro e falo 'ah, mas a aula é muito leve, é muito boa', e isso me traz aqui. Entendeu? Então eu venho para cá às vezes cansada, irritada e eu saio bem, eu saio melhor do que cheguei. Então isso também me traz aqui” (Júlia).

"Eu também. Hoje, por exemplo, eu cheguei aqui morrendo de sono, morrendo em pé, né? E já estou animado, eu já estou entusiasmado. Eu gosto de vir. A aula me deixa mais light, mais relaxado" (Pedro).

"A aula às vezes influencia o dia de trabalho. O dia de trabalho às vezes é pesado, cansativo e você vem para cá e acaba relaxando. E é importante” (Rodrigo).

"E como todos já falaram, a gente vem e aqui a gente relaxa, então, dá uma relaxada na mente. Sai do dia-a-dia e entra numa parte mais gostosa, que é o que nós queremos. A gente está querendo aprender. É uma vontade nossa. E lá não. É uma imposição da empresa. Aqui não, aqui a gente vem porque quer, lá a gente às vezes é obrigado a ficar. É o contrário, aqui a gente relaxa. Eu acho que aqui dá um alívio até para o dia seguinte, para o serviço. É relaxante. $O$ pessoal chega meio cansado e no final da aula, que era para estar todo mundo mais cansado, está todo mundo mais sorridente" (Paulo).

"O trabalho na realidade, para mim, ele influencia momentos antes da aula e nos primeiros cinco minutos. Quando o dia é muito estressante, dificulta um pouco o nível de concentração. Mas depois que encaixa, que você entra na aula, a aula flui normalmente e aí a gente acaba esquecendo dos problemas e acaba melhorando o aprendizado. Só nos primeiros cinco minutos que pode influenciar alguma coisa" (Ricardo).

À luz da hipótese do filtro afetivo de Krashen (1985), pode-se dizer que esse cansaço e estresse proveniente do dia de trabalho dos alunos são outros fatores que se aliam para gerar nos alunos um alto filtro afetivo, o qual, se não fosse de alguma forma trabalhado para ser reduzido, provavelmente faria com que a aprendizagem dos alunos ficasse prejudicada. Provavelmente, dentre outros aspectos, a correspondência existente entre as expectativas dos alunos e os objetivos do curso de língua inglesa que estão fazendo contribui para que esse filtro afetivo seja baixado, assim favorecendo a aprendizagem da língua inglesa.

\section{Considerações finais}

De modo geral, este trabalho mostra que um dos fatores que, de fato, podem influenciar a aprendizagem de uma língua estrangeira em um curso é a correspondência 
existente ou não entre as expectativas dos alunos e os objetivos do curso. A correspondência entre esses dois elementos contribui para que haja aprendizagem, pois ajuda a gerar um baixo filtro afetivo; a não-correspondência, por outro lado, compromete a aprendizagem, pois funciona - juntamente com outros fatores - para gerar um alto filtro afetivo.

Este artigo mostra também a necessidade de realização de outras pesquisas similares para que se tome conhecimento de outros fatores que podem influenciar a aprendizagem de uma língua estrangeira em cursos de idiomas, tanto particulares (na empresa, em casa ou em outros lugares) como em escolas.

Finalmente, pelo fato de tematizar de um modo específico o trabalho de ensinoaprendizagem de línguas estrangeiras que se dá no interior de empresas, muitas vezes por iniciativa de grupos de alunos que contratam diretamente seus professores, espera-se que este texto venha a se constituir como uma pequena contribuição para a reflexão sobre o modo como semelhantes cursos podem ser desenhados e oferecidos, conduzindo os alunos a uma efetiva aprendizagem da língua estrangeira e seus professores a uma maior satisfação ao observar os resultados do trabalho que vão realizando.

\section{Referências}

ALARCÃO, Isabel. Professores reflexivos em uma escola reflexiva. 4. ed. São Paulo: Cortez, 2005.

ALMEIDA FILHO, José Carlos P. Linguística aplicada: ensino de línguas \& comunicação. 2. ed. Campinas, SP: Pontes Editores e ArteLíngua, 2007.

AMORIM, Marília. O pesquisador e seu outro: Bakhtin nas ciências humanas. São Paulo: Musa Editora, 2001.

BAKHTIN, Mikhail. Estética da criação verbal. Tradução de Paulo Bezerra. São Paulo: Martins Fontes, 1979/2003.

CAZDEN, Courtney B. Classroom discourse: the language of teaching and learning. 2nd ed. Portsmouth, NH: Heinemann, 2001.

ELLIS, Mark; JOHNSON, Christine. Teaching business English. New York: Oxford University Press, 1994/1996.

KENEDY, Eduardo. Gerativismo. In: MARTELOTTA, Mário E. (Org.). Manual de linguística. São Paulo: Contexto, 2008. p. 127-140.

KRASHEN, Stephen D. Principles and practice in second language acquisition. New York: Pergamon, 1982.

The input hypothesis: issues and implications. New York: Longman, 1985.

; TERREL, Tracy D. The natural approach: language acquisition in the classroom. New York: Pergamon, 1983. 
KHUWAILEH, Abdullah A. Don't complicate, facilitate: eight ways which complicate ESP students' process of learning. The ESPecialist, PUC-SP, v. 16, n. 1, p. 55-68, 1995.

MACHADO, Anna Rachel. (Org.). O ensino como trabalho: uma abordagem discursiva. Londrina, PR: Eduel, 2004.

MARTON, Waldemar. The anti-pedagogical aspects of Krashen's theory of second language acquisition. In: BARACH, Ronald M.; VAUGHAN, James C. (Orgs.). Beyond the monitor model. Boston: Heinle \& Heinle, 1994. p. 57-69.

MOITA LOPES, Luiz P. Oficina de linguística aplicada: a natureza social e educacional dos processos de ensino/aprendizagem de línguas. Campinas, SP: Mercado de Letras, 1996.

RICHARDS, Jack C.; RODGERS, Theodore S. Approaches and methods in language teaching. 2nd ed. New York: Cambridge University Press, 1986/2008.

RODRIGUES, Neise C.; SÁ CUNHA, Carlos. T. What about the student? The ESPecialist, PUC-SP, n. 10, p. 1-8, 1984.

ROGERS, Carl R. Freedom to learn. Columbus, Ohio: Charles E. Merril Publishing Company, 1969.

RUBIN, Joan; THOMPSON, Irene. How to be a more successful language learner. 2nd ed. Boston, Massachusetts: Heinle \& Heinle Publishers, 1994.

THIOLLENT, Michel. Metodologia da pesquisa-ação. 13. ed. São Paulo: Cortez, 2004.

VIGOTSKI, Lev S. A construção do pensamento e da linguagem. Tradução de Paulo Bezerra. São Paulo: Martins Fontes, 2001. 